\title{
Aprotinin application has no negative effect on osseous implant integration: a biomechanical and histomorphometric investigation in a rat model
}

B. Faensen · C. Hain $\cdot$ J. Höhne $\cdot$ P. Schwabe $\cdot$

N. Haas $\cdot$ G. Schmidmaier $\cdot$ B. Wildemann

Published online: 4 March 2008

(C) Springer-Verlag 2008

Erratum to: Arch Orthop Trauma Surg

DOI 10.1007/s00402-008-0582-1

Due to a processing error Fig. 5 in the print and online version of the publication is wrong. A corrected versions of this figure is reproduced below.

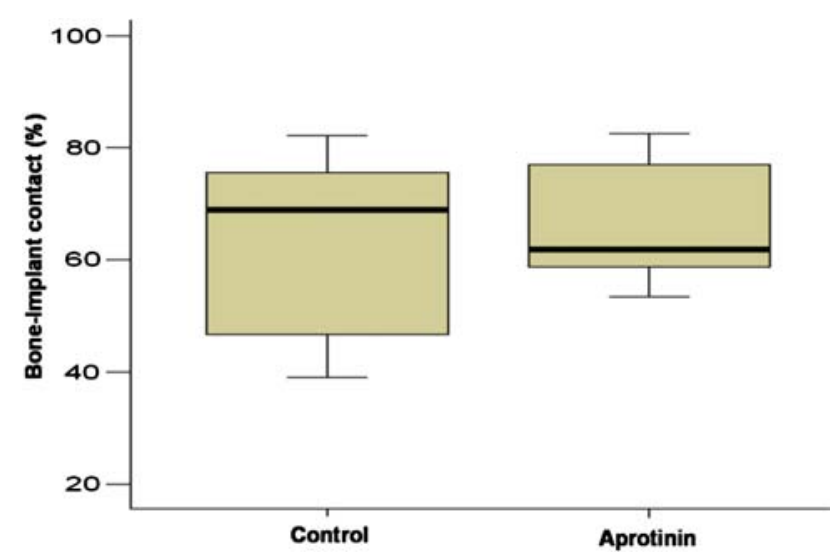

Fig. 5 Comparison of the bone-implant interface. Both groups show similar percentages of contact area

The online version of the original article can be found under doi:10.1007/s00402-008-0582-1.

B. Faensen $\cdot$ C. Hain $\cdot$ J. Höhne $\cdot$ P. Schwabe $\cdot$ N. Haas $\cdot$

G. Schmidmaier · B. Wildemann ( $\square)$

Center for Musculoskeletal Surgery, Universitätsmedizin Berlin,

Charité, Augustenburger Platz 1, 13353 Berlin, Germany

e-mail: britt.wildemann@charite.de 